\title{
Hanging force analysis for realizing low vibration of grape clusters during speedy robotic post-harvest handling
}

\author{
Muhammad Faheem ${ }^{1,2}$, Jizhan Liu ${ }^{1 *}$, Guozheng Chang ${ }^{1}$, Ibrar Ahmad ${ }^{1}$, Yun Peng ${ }^{1}$ \\ (1. Key Laboratory of Modern Agricultural Equipment and Technology, Ministry of Education, Jiangsu University, \\ Zhenjiang 212013, Jiangsu, China; \\ 2. Department of Farm Machinery and Power, University of Agriculture, Faisalabad 38000, Pakistan)
}

\begin{abstract}
Mechanical damage induced by vibration during harvesting and post-harvest handling could decrease the quality, quantity, and shelf life of the fresh grape cluster. Usually, fresh grape clusters are harvested by gripping and cutting from the main rachis in the present robotic harvesting system, then transported towards the basket during post-harvest handling. However, serious cluster vibration and corresponding berry falling may occur during the robotic transportation of hanging grape clusters. Therefore, this study was designed to perform experimental and theoretical hanging force analysis to explore the vibration mechanism of hanging grape clusters during robotic transportation. A lead screw lathe with an attached linear actuator was used to investigate the effects of four different speeds $(0.4,0.6,0.8,1.0 \mathrm{~m} / \mathrm{s})$ with four acceleration levels $\left(6,8,10,12 \mathrm{~m} / \mathrm{s}^{2}\right)$ on the vibration of the hanging grape cluster. By the experiments, the peak hanging force of the grape cluster at the start, constant speed, and stop phase of the actuator was recorded using a single axis force sensor, and the cluster's swing angle was measured with a digital camera. The experimental results showed a linear relationship between the swing angle and hanging force of the cluster at the start and stop phase of the actuator. The multi-stage cluster's vibration during robotic transportation was observed, and the behavior of cycled damping after a sudden stop of the actuator was found. The simulated results of hanging force of grape cluster in damping phase were agreed with experimental results with $R^{2}$ more than 0.90 at an optimum acceleration of $10 \mathrm{~m} / \mathrm{s}^{2}$. To conclude, this research provides theoretical basics for understanding the complex vibration mechanism of the hanging cluster fruits during speedy robotic transportation operations with low-loss of berry drop both on industrial and farm levels.
\end{abstract}

Keywords: grape cluster, vibration mechanism, hanging force, force sensor, robotic transportation, robotic handling DOI: $10.25165 /$ j.ijabe.20211404.6406

Citation: Faheem M, Liu J Z, Chang G Z, Ahmad I, Peng Y. Hanging force analysis for realizing low vibration of grape clusters during speedy robotic post-harvest handling. Int J Agric \& Biol Eng, 2021; 14(4): 62-71.

\section{Introduction}

Grape occupies an important place in the world, its annual output has reached 79 million $\mathrm{t}^{[1]}$. Grape species and cultivars can be classified into four main groups for food usage: table grapes, wine grapes, juice grapes, and raisin grapes ${ }^{[2]}$. Among these, table grapes occupy an important place in the world's cluster fruits production, and more than $65 \%$ of the grapes produced are consumed as fresh eating fruit ${ }^{[3]}$. Fresh eating grape yields are enhanced with the development of the grape industry ${ }^{[4]}$.

Compared with wine grapes which are harvested and transported in the form of berries, the harvest and post-harvest handling of fresh eating grapes must be completed in the form of clusters or bunches until they are put in the supermarket. In robotic handling of grape clusters during harvesting and post-harvesting operations, the "stem gripping" method (for single

Received date: 2021-01-06 Accepted date: 2021-04-02

Biographies: Muhammad Faheem, PhD, Assistant Executive Engineer, research interest: farm mechanization and robotic harvesting, Email: engr.faheem@uaf.edu.pk; Guozheng Chang, Master candidate, research interest: robotic harvesting and transplanting, Email: 928211863@qq.com; Ibrar Ahmad, $\mathrm{PhD}$, research interest: robotic transplanting and harvesting, Email: ibrar.ahmad@yahoo.com; Yun Peng, PhD, research interest: robotic harvesting and image analysis, Email: 215497226@qq.com.

*Corresponding author: Jizhan Liu, Professor, research interest: robotic transplanting, harvesting, planning and navigation. No. 301 Xuefu road, Zhenjiang, Jiangsu 212013, China. Tel: +86-511-88797338, Fax: +86-51188797338, Email: liujizhan@163.com. fruits $)^{[5]}$ is usually not used, but the main rachis is directly gripped and cut. The hanging grape cluster after cutting is transported towards a box, released and placed into a basket to complete on-site transportation (as shown in Figure 1). However, berry drop or shatter may occur during these robotic handling operations due to the vibration of the grape cluster. For long-distance transportation that including processing, packaging, storage, and logistics operations, the probability of berry drops would greatly increase, which may also increase the handling of the cluster fruits ${ }^{[6-14]}$. The loss caused by berry drop and decay of fruit is up to $20 \%$ to $30 \%$, the integrity of fresh cluster fruits and non-destructive evaluation are two major quality criteria for grape cluster fruit ${ }^{[15]}$. The problem of berry falling, breaking of fresh grapes has seriously affected its shelf life and marketability ${ }^{[9,16,17]}$, which has become a serious problem that has plagued the fresh grape cluster fruits industry chain for a long time. It has become a key obstacle to the development and control of harvesting and post-harvesting robotic tools for the handling of fresh cluster fruits.

In order to solve the problem of grape berry drop and decay, significant researches have been carried out on the impact and vibration damage of the grapes during harvest and postharvest mechanical handling, i.e., Pezzi et al. ${ }^{[18]}$ and Caprara et al. ${ }^{[19]}$ used electronic fruit to investigate the collision of fresh grapes during mechanical harvesting and transportation. Yue et al. ${ }^{[20]}$ found that the dropping impact of grape berry has a significant impact on physiological quality during storage and transportation. Bian et al. ${ }^{[21]}$ studied the influence of drop height on the dielectric 
properties of red globe grapes. Vinokur et al. ${ }^{[22]}$ found the berry falling rate was directly proportional to the free-falling height. Jung et al. ${ }^{[2]}$ evaluated the effect of vibration stress on the quality of packaged grapes using simulated transportation. Vallone et al. ${ }^{[23]}$ measured acceleration effect on the mechanical harvesting of grapes by using an instrumented sphere. Deng et al. ${ }^{[3]}$ developed a mathematical model to predict the grape berry drop during storage. Fischer et al. ${ }^{[24,25]}$ determined the critical frequencies for grapes and strawberries fruit shattering during transportation of distribution. $\mathrm{HaO}^{[26]}$ found that the greater the vibration acceleration was, the greater the damage to the Kyoto grapes was during storage and road transportation. Demir et al. ${ }^{[27]}$ calculated the natural frequency of grape, and berry drop during simulated transportation environmental. But the above studies deal with the impact of mechanical handling on the harvest and post-harvest quality and berry drop damage of fresh grape clusters.

In robotic hanging handling, grape clusters are hung or clamped from the main rachis after harvest and being transported towards a box ${ }^{[7]}$ as shown in (Figure 1). Although robotic handling of hanging cluster fruits can overcome bruising and abrading damage, the potential problems like the vibration of the cluster and corresponding berry falling attract more and more attention in the field of robotic post-harvest handling. It is an important handling option in practice both on industrial and farm levels. For robotic harvesting of a single fruit, several researchers conducted different studies on fruit falling damage caused by vibration of the fruit that might be happened in stem gripping and cutting $^{[7,28-35]}$ of a single fruit. Robotic post-harvest handling practices with hanging cluster fruits are few in the application where the gripping or holding force will be applied to a particular cluster part (rachis) bearing all the weight of the cluster ${ }^{[29,36-41]}$. Therefore, the reliability and damage ratio needs to be examined ${ }^{[42]}$. Kondo et al. ${ }^{[40]}$ obtained results from the experiments that increasing the robotic transportation speed of the hanging tomato cluster would cause the vibration of the cluster, and fruit falling. Liu et al. ${ }^{[43]}$ found that acceleration and deceleration would become the reason for the vibration of the grape cluster and berry falling in high-speed photography experiments. Therefore, understanding the vibration mechanism, and ensuring the lower ratio of berry falling during robotic transportation has a great value to improve the performance of the robotic post-harvest handling of cluster fruits both on the industry level and on-site field.

The impact of robotic post-harvest handling on the berry drop of the hanging cluster fruits is mainly related to the field of mechanical vibratory harvesting and post-harvesting. To discover the inner vibration mechanism of hanging stem fruits (single fruits) under different excitations, several researchers ${ }^{[33,35,44-50]}$ have been involved in mechanical modeling and simulation of hanging "stem-fruits" systems. They described the properties of the fruit and stem, and the connection strength of the branch. For the motion of the stem fruits in vibration, some researchers ${ }^{[47,49,51,52]}$ thought it was very complex. They described five patterns of vibrating fruits, in which bending and swinging had a significant effect on the falling of the stemfruit. The above researchers mainly focused on the vibration excitation characteristics, vibration transmission through a single stem fruit system, which is obviously different from the coupling vibration response of the complex cluster fruits like redcurrant, rubus, lychee, tomato, longan, etc. ${ }^{[53]}$, during robotic post-harvest transportation handling.

Theoretical modeling and simulation of the hanging cluster ruits are powerful tools for understanding the vibration and berry dropping mechanism during robotic transportation of cluster fruits. Liu et al. ${ }^{[7]}$ firstly developed a compound mechanical model of a grape cluster, then carried out simulation and experimental analysis under different excitations in the transportation phase after cutting to observe the swing angle for each berry of the cluster. However, the vibration mechanism of the whole cluster, characteristics, hanging force for supporting grape cluster, and the effect of swing angle on the main rachis bending during robotic post-harvest transportation are still remaining unexplored.

The vibration of the cluster fruits has a significant effect on the loss of control during robotic post-harvest handling both on industrial and farm levels. In this context, the main aim of the study was to analyze the behavior of grape cluster vibration in different phases of linear transportation of the actuator. The effect of different speed and acceleration excitations on the grape cluster and hanging force (the force that bears the weight of the gripped grape cluster against gravity during robotic transportation) was observed. The relationship between swing angle and hanging force of the grape cluster was analyzed to understand berry falling and rachis bending mechanism. Furthermore, the experimental results combined with simulated results of cluster hanging force by using cyclic damping model was obtained for the verification of vibration falling mechanism. Overall, this study provides theoretical support for the industries to optimize the berry falling loss of different cluster fruits during robotic transportation handling, and suggests a safe zone and excitation at which chances of damages will be minimized.

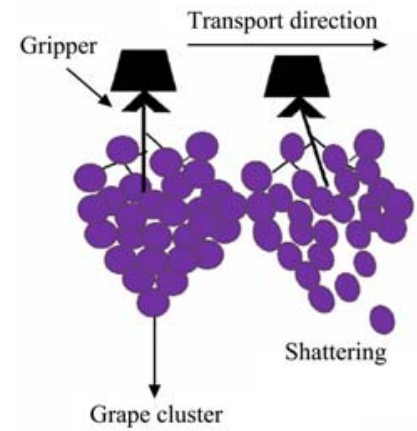

Figure 1 Vibration damage of hanging grape cluster during robotic transportation

\section{Materials and methods}

\subsection{Stalk structure of the grape cluster}

The study was conducted in the Key Laboratory of Modern Agricultural Equipment Engineering designated by the Ministry of Education, Jiangsu University, Zhengjiang, Jiangsu, China. An artificial grape cluster with a mass of $506 \mathrm{~g}$ was used for the experiments and analysis, there were about 85 berries in the cluster that were filled with soil manually to maintain weight just like a real grape cluster, and each berry weighted 4-5 g measured with digital weight balance (BP Professional Electronic Balance BP-6228, accuracy $0.01 \mathrm{~g}$ ). The cluster has many sub-rachis separated from the main rachis whose diameter $(2.28 \mathrm{~mm})$ was measured with a vernier caliper (accuracy $+0.02 \mathrm{~mm}$ ). Every sub rachis has several stems with attached berries at the pedice ${ }^{[54,55]}$ as shown in Figure 2a. The experimental setup included a lead screw lathe with attached one degree of freedom (1 DOF) actuator, programmable logic controller (PLC), a clamp, a single axis force sensor (Model: MIK LCS1, range $0-5 \mathrm{~kg}$ with $0.03 \%$ full-scale error) that was installed between the grape cluster and clamp, as shown in Figure $2 b$. 


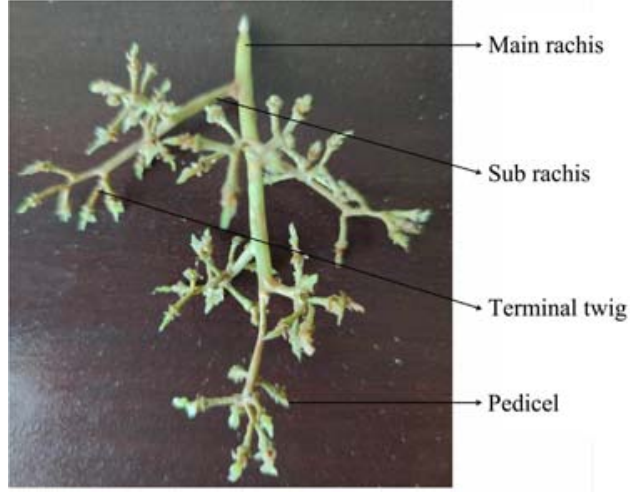

a. Stalk structure of the grape cluster

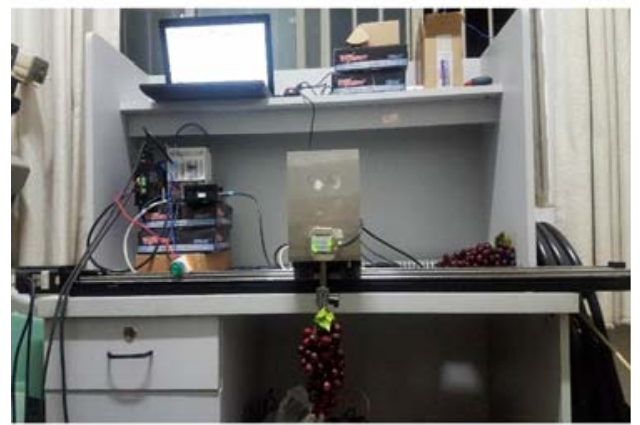

b. Experimental setup

Figure 2 Material and experimental setup for hanging force analysis of grape cluster

\subsection{Experimental observation of cluster's vibration and} hanging force

An artificial grape cluster was used as experimental material because the study aimed to analyze the vibration mechanism of the hanging grape cluster during different zones of robotic linear transportation that was difficult by using a real grape cluster. Since the real cluster will be damaged in the experiments, which will lead to the change of conditions, the results of different excitation treatments cannot be put together to compare and analyze. For understanding the vibration mechanism of the grape cluster, the actuator was moving horizontally on the rails of the lead screw lathe according to the input speed and acceleration excitations from the PLC as shown in Table 1. Due to the actuator movement, the excitations were transferred from the clamp to the berries through main rachis, and the hanging grape cluster started to vibrate as shown in Figure 3a. Firstly, the force exerted on the hanging grape cluster during the linear transportation was measured with the single-axis force sensor. The excitation displacement or stroke length was adjusted to $800 \mathrm{~mm}$ from start to stop point.

The peak hanging force of the grape cluster during accelerating (start), constant speed, and deaccelerating (stop) time phase of the actuator was determined as shown in Figure 3b. Then, the safe time phase and excitation at which the amplitude of the cluster's vibration was low were analyzed. The state of the hanging grape cluster was recorded with a digital video camera, and the vibration amplitude of the hanging grape cluster was analyzed and explained from camera images and data acquisition card (DAC) software that showed force signals in the digits form. Theoretical analysis was also done for different zones during linear transportation of the actuator. The experimental results of the cluster's hanging force combined with simulated results by using damping model to see the goodness of fit were obtained, and the berry falling mechanism due to serious vibrations of the hanging grape cluster was verified.

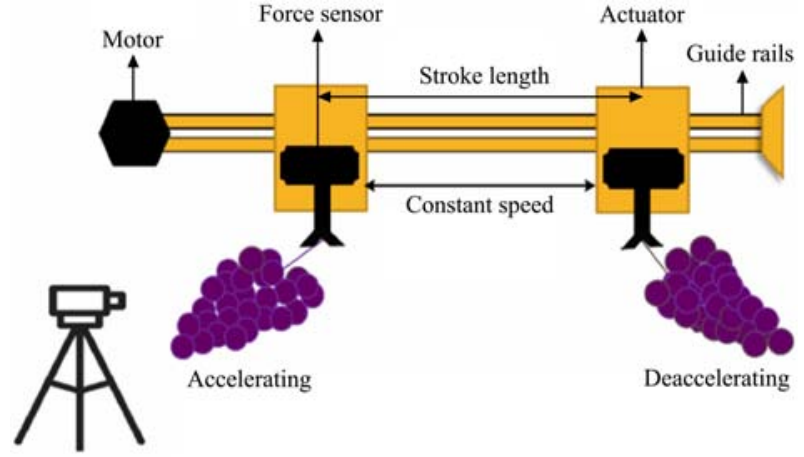

a. Schematic diagram of experimental observation of cluster's vibration at accelerating and deaccelerating of actuator

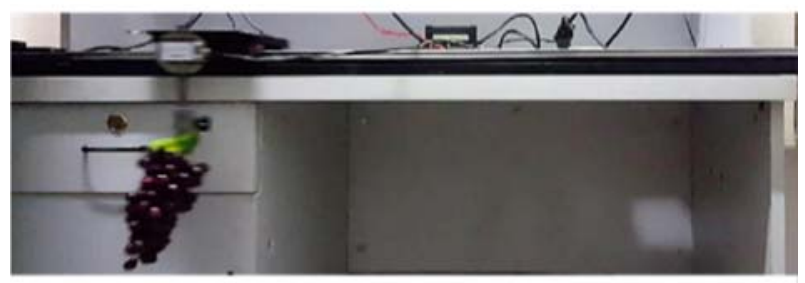

Accelerating phase

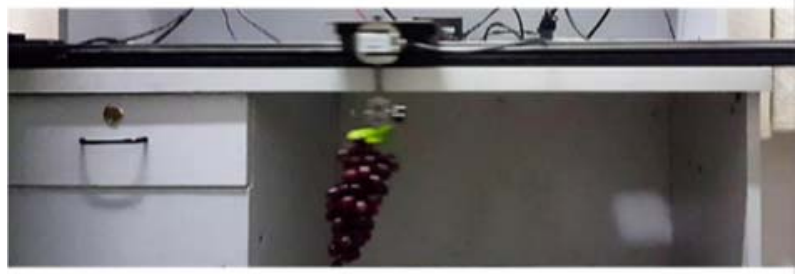

Constant speed phase

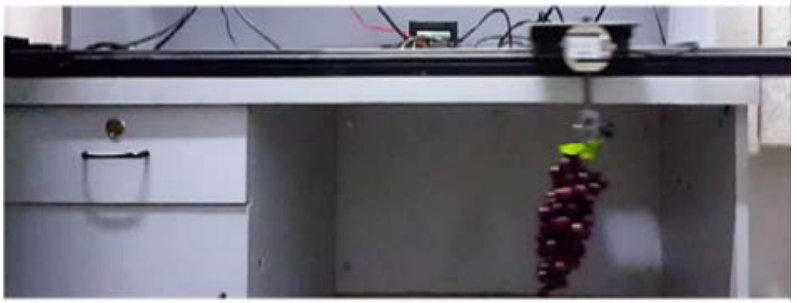

Deaccelrating phase

b. Time phases of grape cluster during linear transportation

Figure 3 Hanging force analysis in different phases of linear transportation of grape cluster

Table 1 Different excitations to actuator

\begin{tabular}{cccc} 
Speed $/ \mathrm{m} \cdot \mathrm{s}^{-1}$ & Accelerated speed $/ \mathrm{m} \cdot \mathrm{s}^{-2}$ & Accelerated time $/ \mathrm{ms}$ & Duty cycle/s \\
\hline \multirow{3}{*}{0.4} & 6 & 66.66 & 2 \\
& 8 & 50.00 & 2 \\
& 10 & 40.00 & 2 \\
0.6 & 12 & 33.00 & 2 \\
\hline \multirow{3}{*}{0.8} & 6 & 100.00 & 1.33 \\
& 8 & 75.00 & 1.33 \\
& 10 & 60.00 & 1.33 \\
& 12 & 50.00 & 1.33 \\
\hline \multirow{3}{*}{0} & 6 & 133.00 & 1 \\
& 10 & 100.00 & 1 \\
& 12 & 80.00 & 1 \\
\hline & 6 & 66.00 & 0.80 \\
& 8 & 166.00 & 0.80 \\
& 10 & 125.00 & 0.80 \\
& 12 & 100.00 & 0.80 \\
\hline
\end{tabular}

Note: Duty cycle is the time taken by the actuator to complete one stroke. 


\subsection{Experimental observation of the cluster swing angle}

The swing angle of the grape cluster at different speeds $(0.4$, $0.6,0.8,1.0 \mathrm{~m} / \mathrm{s})$ and acceleration $\left(6,8,10,12 \mathrm{~m} / \mathrm{s}^{2}\right)^{[45]}$ during linear transportation of the actuator was recorded and observed by using a digital camera. During the analysis of camera images, the swing angle $(\theta)$ of the grape cluster at extreme position $\mathrm{P}_{2}$ from the mean position $\mathrm{P}_{1}$ was calculated with the help of a protector (Figure 4a). Due to the high friction of the guide rails and static load of the actuator at the start and stop, the swing angle of the cluster was observed high as shown in Figure $4 \mathrm{a}$. The bending load on the main rachis was from two points: the gripping point and the point just above berries. Twisting of the cluster was also observed during experiments as shown in Figure 4. The relation between swing angle and hanging force of the cluster was investigated to find the safe zone at which the hanging grape cluster vibrated with low amplitude.

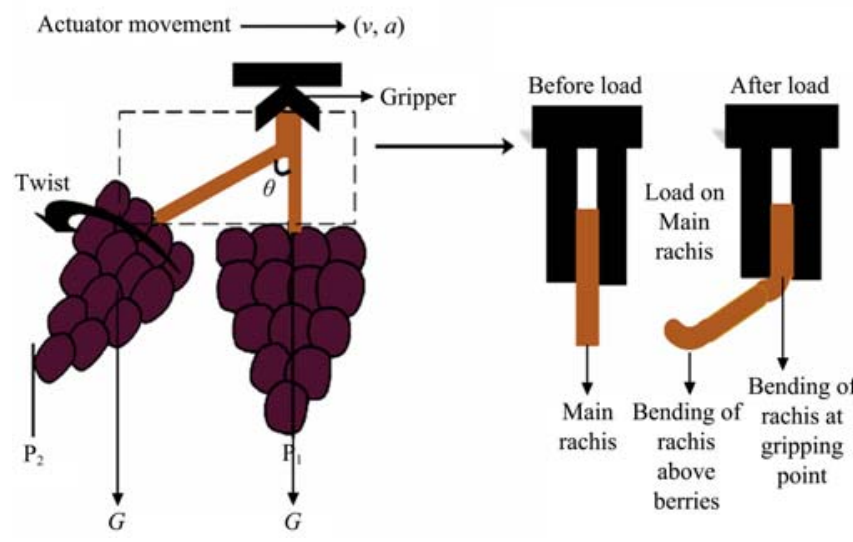

a. Swing angle of the grape cluster

b. Bending load on the main rachis Note: $v$ is speed; $a$ is acceleration; $\theta$ is swing angle of the grape cluster; $G$ is gravity; $\mathrm{P}_{1}$ and $\mathrm{P}_{2}$ are extreme positions of grape cluster before and after load.

Figure 4 Observation of swing angle of grape cluster and bending load on main rachis during linear robotic transportation

\section{Results}

\subsection{Experimental results}

3.1.1 Effect of different excitations on peak hanging force

It was observed from the experiments that at input excitations of $0.4,0.6,0.8,1.0 \mathrm{~m} / \mathrm{s}$ and $6,8,10,12 \mathrm{~m} / \mathrm{s}^{2}$, the amplitude of the cluster's vibration was maximum at the start and stop of the actuator movement ${ }^{[56]}$. That was due to the air resistance and friction of the guide rails ${ }^{[57]}$ on which the actuator moved. It was found from the experimental analysis that the magnitude of cluster's hanging force at either the start or stop time phase of the actuator was positively correlated with input speed and acceleration (Figure 5). The magnitude of the hanging force was observed higher in the deaccelerating phase, i.e., around $12 \mathrm{~N}$ at an excitation speed of $1.0 \mathrm{~m} / \mathrm{s}$, compared to that in the accelerating phase, i.e., around $9 \mathrm{~N}$ at the same excitation speed as shown in Figure 5. These results suggest that deaccelerating phase causes serious vibrations of the grape cluster, and more berry fall would happen in this phase of robotic transportation.

3.1.2 Effect of different excitations on swing angle of grape cluster

The experimental results indicated that the swing angle of the grape cluster was positively correlated with excitation speed. It can be seen from Figure 6 that the mean swing angle under different speeds of the actuator $(0.4,0.6,0.8,1.0 \mathrm{~m} / \mathrm{s})$ during the accelerating and deaccelerating phase were $31^{\circ}, 37^{\circ}, 42^{\circ}, 45^{\circ}$, and $32^{\circ}, 43^{\circ}, 56^{\circ}, 59^{\circ}$, respectively. Also, it is observed from Figure $6 \mathrm{a}$ that the swing angle increased when increasing the acceleration excitations, and reached the maximum at $10 \mathrm{~m} / \mathrm{s}^{2}$ during the accelerating phase, but again decreased at acceleration excitation of $12 \mathrm{~m} / \mathrm{s}^{2}$ at each speed. This decrement in swing angle was due to swinging of the cluster in other directions resulted from twisting of the main rachis at high speed and acceleration of the actuator. However, in the deaccelerating phase at high speeds shown in Figure 6b, high air resistance and friction of the guide rails deflected the values of hanging force as compared to the accelerating phase. The results of the swing angle suggested that the optimum acceleration was $10 \mathrm{~m} / \mathrm{s}^{2}$, at which the grape cluster swung in one direction with minimum twisting of the main rachis. Therefore, the chances of berry drop would be minimized.

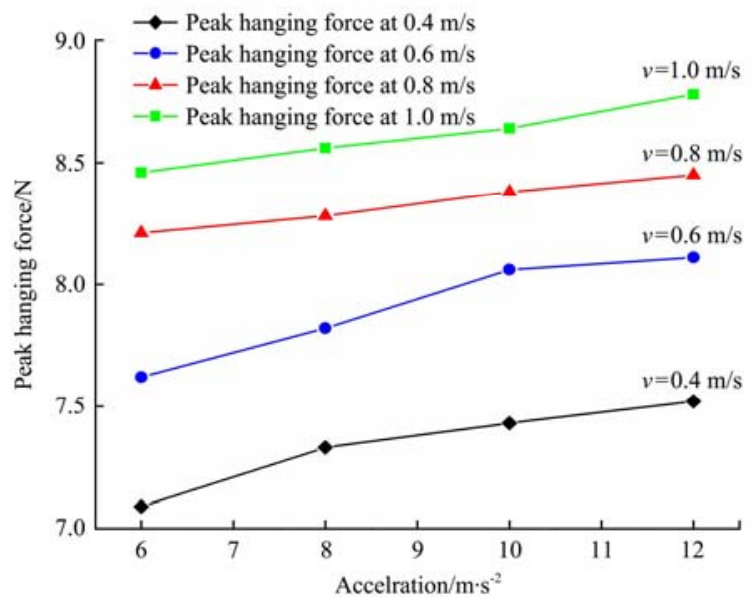

a. Accelerating phase (start phase)

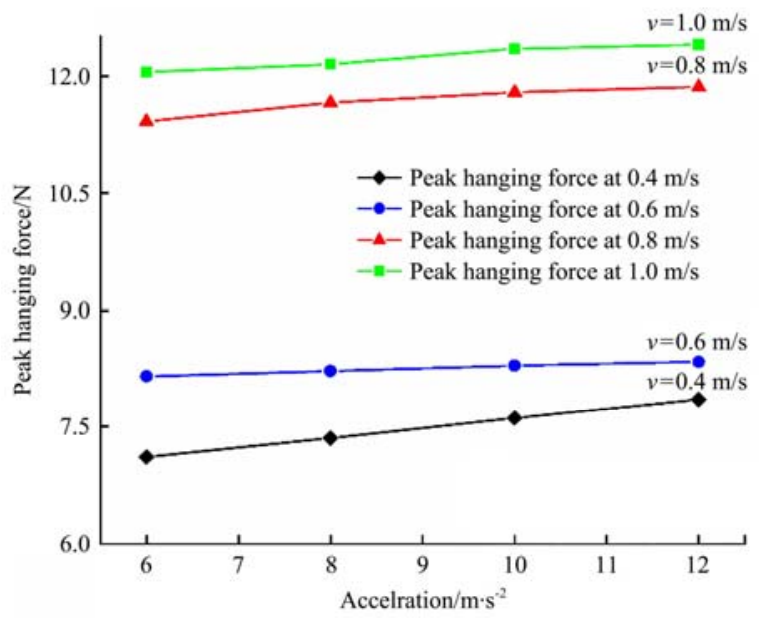

b. Deaccelerating phase (stop phase)

Figure 5 Peak hanging force at different acceleration excitations in different time phases

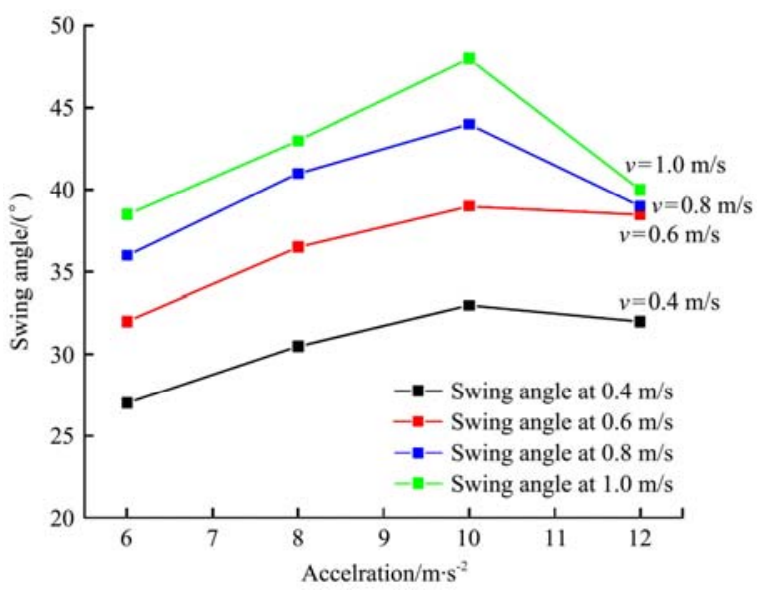

a. Accelerating phase 


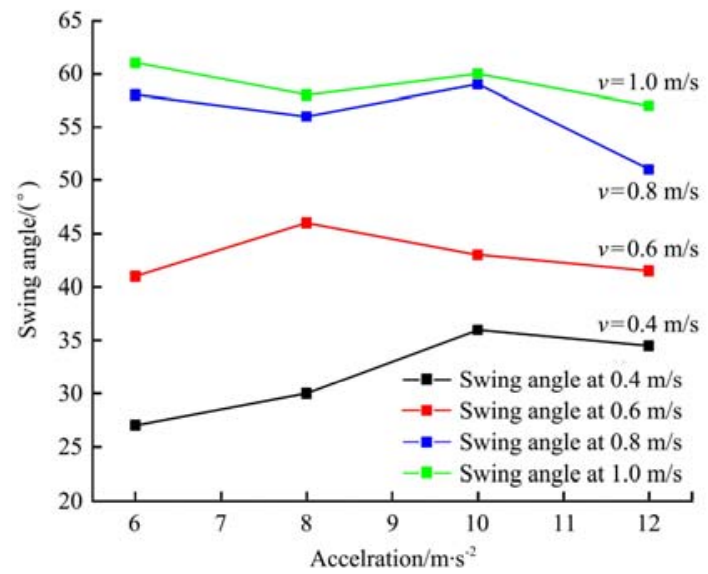

b. Deaccelerating phase

Figure 6 Swing angle at different speed and acceleration excitations in different time phases

\subsubsection{Analysis of bending load on grape cluster}

The swing angle of the grape cluster was observed from the images of the digital camera under different speed excitations $(0.4$, $0.6,0.8,1.0 \mathrm{~m} / \mathrm{s}$ ) during the deaccelerating phase as shown in Figure 7. During the analysis of the images and videos, it was observed that the maximum bending angle of the main rachis occurred during the start and stop of the actuator, and even more bending angle during the stop (deaccelerating) phase occurred. The kinetic energy of the actuator was transmitted to the hanging grape cluster and it caused the grape cluster to vibrate with a high swing angle during the deaccelerating phase. These results suggest that during the deaccelerating phase bending load on the main rachis of grapes is maximum that causes maximum berry falling.

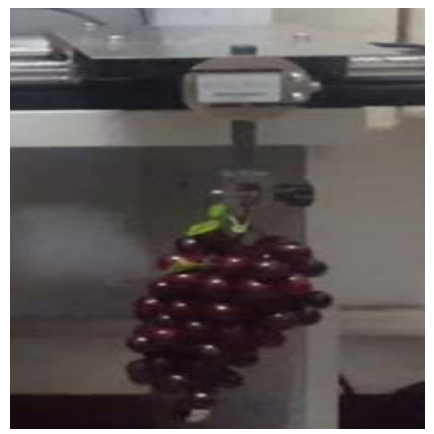

a. $v=0.4 \mathrm{~m} / \mathrm{s}$

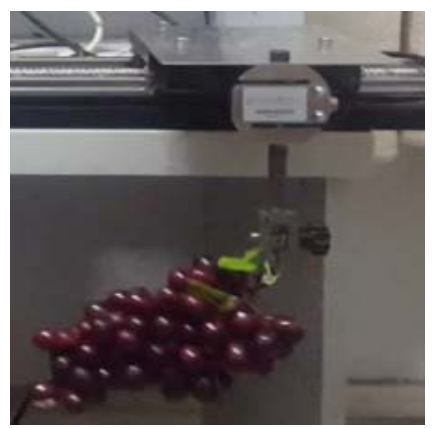

c. $v=0.8 \mathrm{~m} / \mathrm{s}$

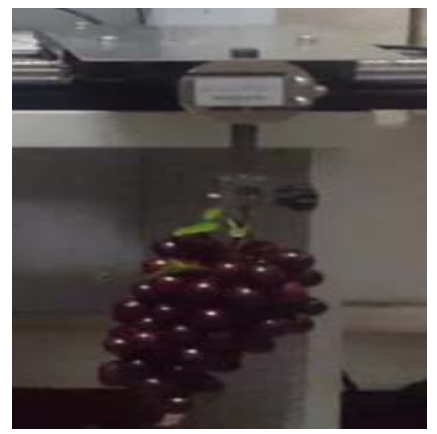

b. $v=0.6 \mathrm{~m} / \mathrm{s}$

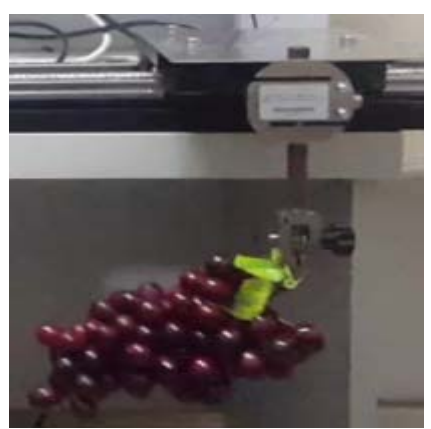

d. $v=1.0 \mathrm{~m} / \mathrm{s}$
Figure 7 Swing angle at different speed excitations

3.1.4 Relationship between hanging force and swing angle

From the statistical analysis, it was found a linear relationship between the hanging force and swing angle of the grape cluster existed both at the start and stop of the actuator with $R^{2}=0.993$ and 0.964 as shown in Figure 8. Also, the swing angle of the grape cluster was observed under sixteen different treatments of speed and acceleration excitations as shown in Figure 8. The swing angle of the grape cluster was observed higher at the stop phase than that at the start phase. The results indicate that the swing angle increases with the increase of hanging force and serious vibration of the grape cluster can result in increased berry drop.

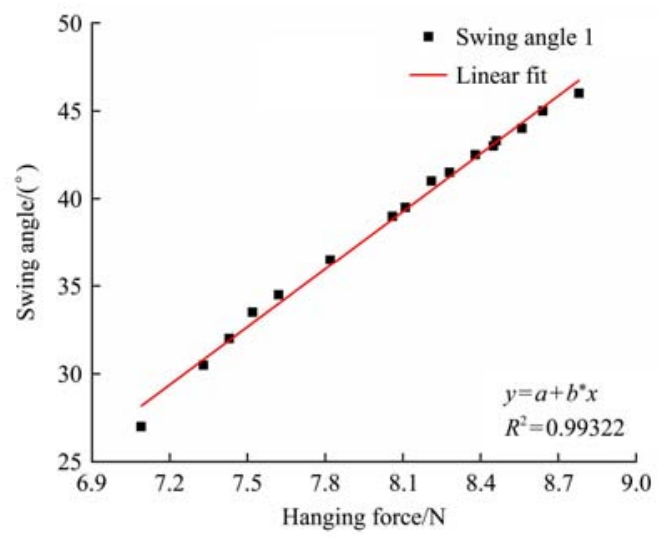

a. Accelerating phase

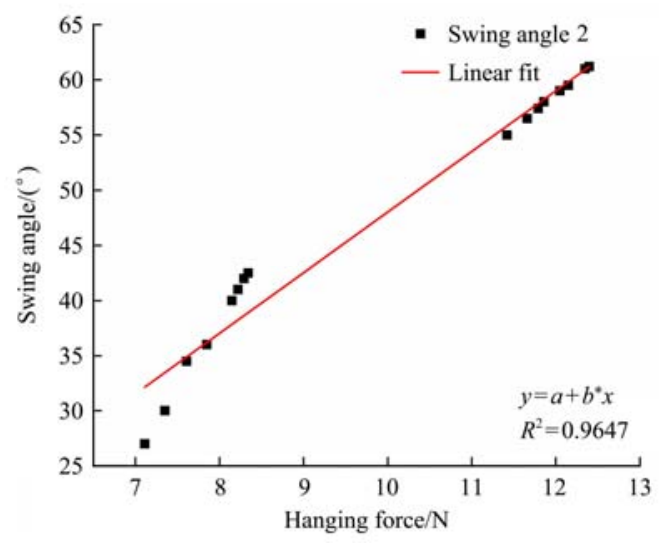

b. Deaccelerating phase

Figure 8 Relationship of swing angle and hanging force of cluster in different time phases

\subsection{Theoretical analysis}

\subsubsection{Vibration characters at different phases}

When the actuator was moving from point 0 to point $\mathrm{c}$ as shown in Figure 9a, the hanging cluster started to vibrate, and the force sensor measured the hanging force of the cluster in the form of analogue signals. These force signals were divided into 5 zones as shown in Figure 9b, for better understanding of the inner vibration mechanism of the hanging grape cluster at different stages of robotic transportation.

Zone 1 (Stationary phase of the hanging grape cluster): In this zone hanging grape cluster was at stationary position with its static weight, and force signals showed the calibrated value of $506 \mathrm{~g}$ cluster was around $6.17 \mathrm{~N}$.

Zone 2 (Accelerating phase): In this zone, excitations applied to the actuator, it started to move from position 0 to a. Due to the actuator's movement, the hanging grape cluster started to vibrate. The magnitude of force signals was high in this zone because the hanging cluster suddenly started to vibrate from a stationary state.

Zone 3 (Constant speed phase): between Zone 2 and Zone 4, the cluster moved with low or constant amplitude vibration due to the short time interval of the actuator's movement, and the magnitude of hanging force signals was observed constantly.

Zone 4 (Deaccelerating phase): In the next phase, when the actuator was stopped at position c, a dramatic increment in the magnitude of the hanging force signals was observed that showed 
the hanging grape cluster reached maximum amplitude (highest position) during deaccelerating of the actuator.

Zone 5 (Damping phase): After the actuator stopped in Zone 4, all the kinetic energy of the actuator transmitted into hanging grape cluster that pushed the hanging grape cluster around a position like a pendulum motion with a natural frequency. The kinetic energy of the actuator was converted into the potential energy of the hanging cluster. After some time, the grape cluster reached the mean position due to loss of stored energy caused by medium resistance and cluster weight, and showed the damping behavior. It was cycled vibration, and showed damping behavior until the grape cluster stopped without energy input. The experimental results of this damping phase were compared with simulated results to verify the vibration falling mechanism.

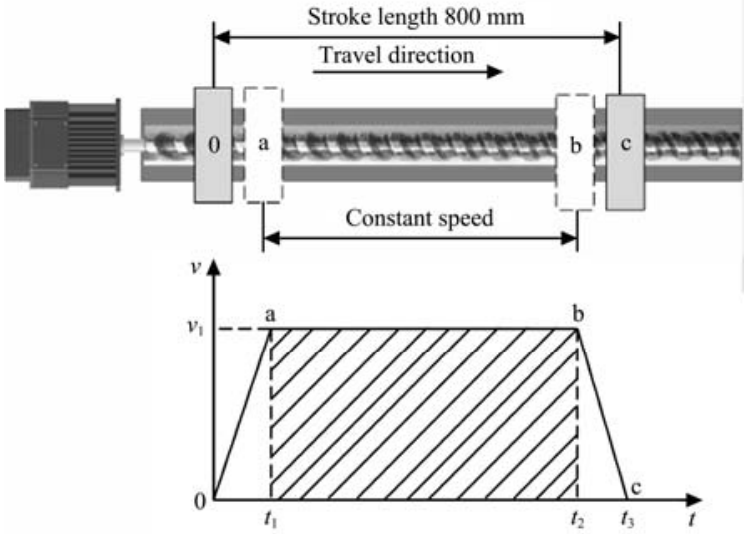

a. Velocity trapezium of actuator's movement

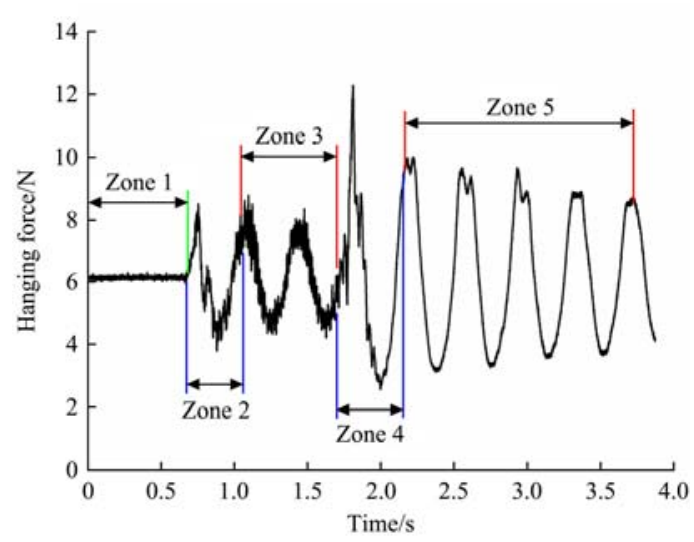

b. Force sensor signals

Figure 9 Hanging force zones of grape cluster during robotic linear transportation

\subsubsection{Cycled damping vibration}

1) Trend of natural damping

For the verification of experimental results of damping zone with a simulation model to see the goodness of fit and how close the results are. Firstly, the amplitude of peak hanging force points $A_{1}, A_{2}, A_{3}, A_{4}, A_{5}, A_{6}, A_{7}$ from the force signals of hanging cluster through GETDATA software ${ }^{[58]}$ was determined as shown in Figure 10a. Then, a graph between these peak force points and time intervals accordingly was drawn using the curve fitting tool (CFT) on Matlab to fit the selected data as shown in Figure 10b. An exponential decay relationship between peak points of hanging force and time interval at different excitations was observed in Zone 5. The exponential decay model characteristic was expressed as:

$$
F\left(t_{i}\right)=a \times e^{-b t_{i}}+c_{1}
$$

where, $t_{i}$ is the time that peak hanging force of cluster appears in each cycle, $\mathrm{s} ; i=1,2, \ldots ; F\left(t_{i}\right)$ is the peak hanging force of cluster in each cycle, $\mathrm{N} ; a$ is the amplitude of hanging force, $\mathrm{N} ; b$ is the damping coefficient; $c_{1}$ is the mean or center value of cluster hanging force or calibrated weight force of the hanging grape cluster, N, as shown in Figure 10c.

$$
t_{i}=t_{i-1}+y \quad(i=1,2, \ldots)
$$

where, $y$ is the time period for one cycle, $\mathrm{s}$.

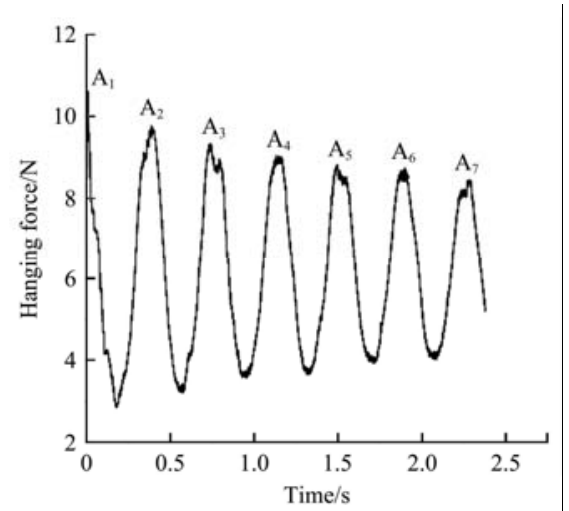

a. Hanging force overtime from experiment

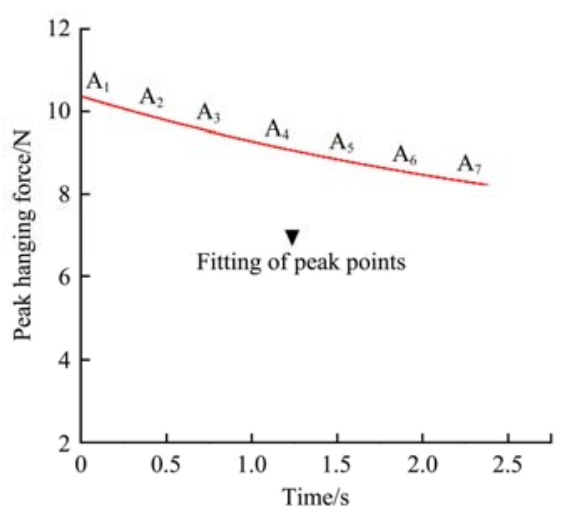

b. Fitting curve of peak hanging force

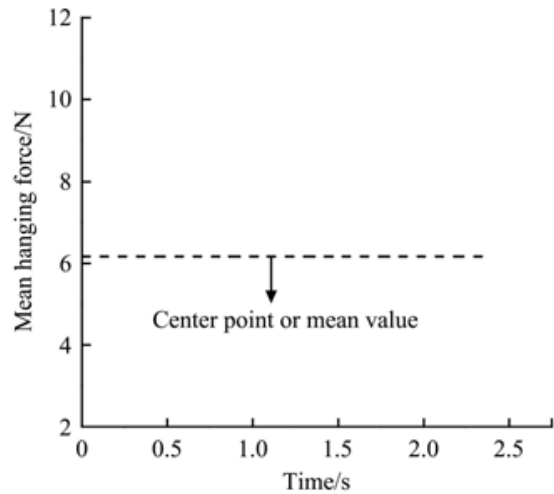

c. Average value of hanging force

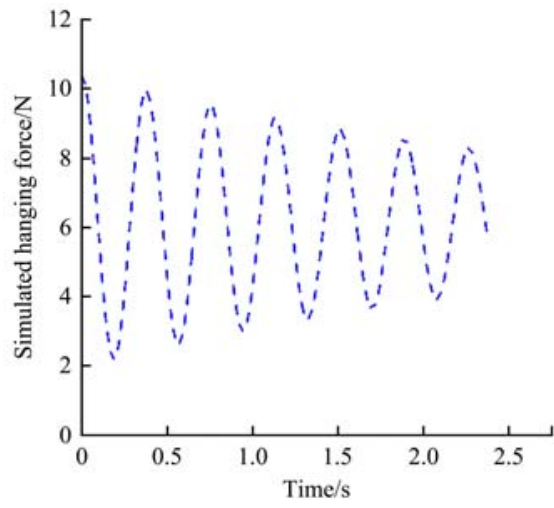

d. Simulated hanging force

Figure 10 Experimental and simulated results relationship for hanging force of grape cluster 
2) The natural cycled damping

It was found with experimental results shown as Figure 9 that in Zone 5, after the stop of the actuator, the cluster vibrated with natural frequency showed a damping behavior until stop. To express the force signals, the damping should be combined with the cyclicity. Therefore, the kinematic equation of the damped oscillator in Equation (3) was used to simulate the hanging force signals in the damping phase as shown in Figure 10d.

$$
F(t)=a \times e^{-b t} \times \cos C t+c_{1}
$$

where, $a \times e^{-b t}$ is the decaying amplitude; $\cos C t$ is the oscillating piece; $C$ is the natural frequency of the cluster $(\mathrm{Hz})$ which can be found by

$$
C=\frac{2 \pi}{y}
$$

\subsubsection{Start-stop excitation vibration test of grape cluster}

The force signal results obtained from the experimental tests in the damping zone were compared with simulated results from cycled damping model as shown in Figure 11b. They were almost the same that satisfied the vibration law or vibration falling mechanism. The vibration damping characteristics after deceleration shock obtained by the force signal curve depended on the natural frequency of the grape cluster. The maximum amplitude of vibration at different acceleration and deceleration shocks were $A_{1}, A_{2}$. The respective vibration-damping curve with natural frequencies $f 1(1 / y), f 2(1 / y)$ of the hanging grape cluster during the constant speed of the actuator and after the stop of the actuator as shown in Figure 11a. Figure 11a shows the cluster's vibration signals of all the 5 zones in which the constant speed phase of the hanging cluster was compared with that of the actuator's motion $\left(T_{2}\right.$ to $\left.T_{3}\right)$.

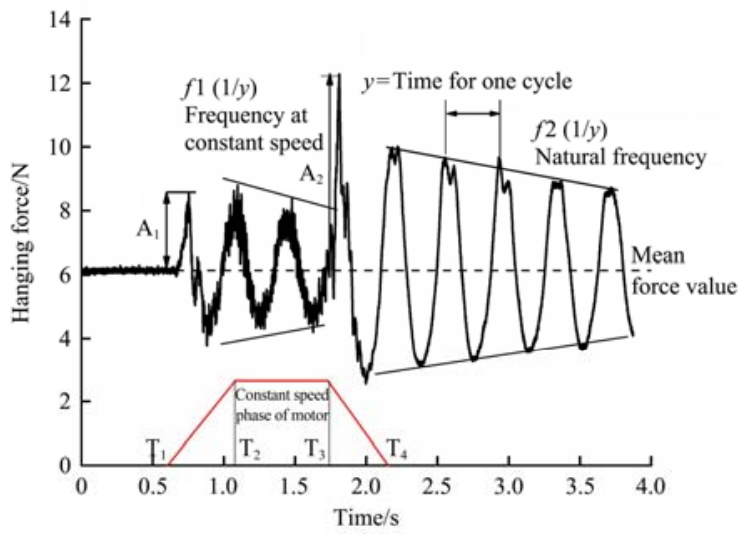

a. Force signals in multistage

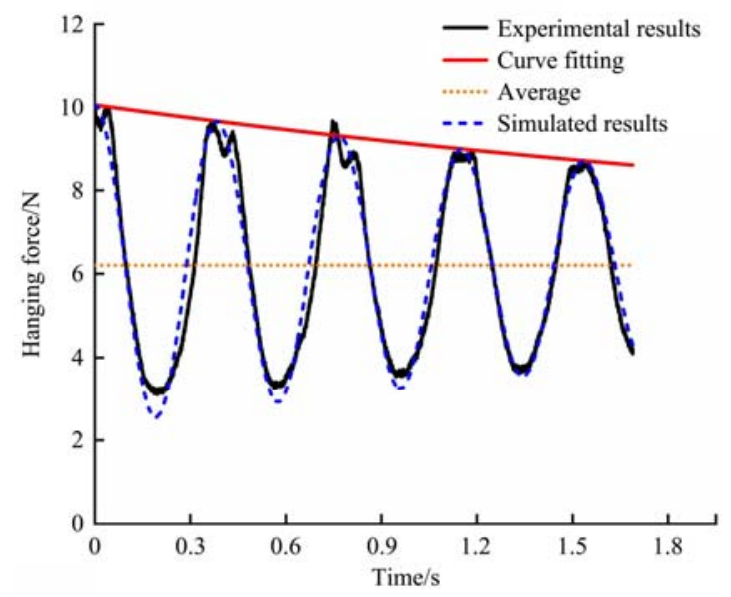

b. Force signal analysis in damping zone

Figure 11 Start-stop excitation vibration test of grape fruit cluster

\subsubsection{Law of vibration attenuation (Fitting results)}

1) Vibration attenuation in a constant speed phase

Based on the hanging force signals, cluster vibration characteristics under different excitations were analyzed. It was observed from the force signals that the behavior of grape cluster vibration in the constant speed phase was not uniform due to the short time interval. Fluctuations or constant amplitude vibrations were observed because the hanging cluster vibrated quickly. The single-axis force sensor showed some disturbing behavior that was not damped and cannot be measured or simulated accurately with the cyclic damping model.

2) Vibration attenuation after a sudden stop

It can be observed from Figure 12 that simulated model results generally agreed well with the experimental observations in Zone 5 (damping zone) for all 16 treatments with the goodness of fit $\left(R^{2}\right)$ greater than 0.90 . These results satisfied the vibration falling mechanism of cluster fruits spatially and temporally, except for some values at lower speed inputs from the motor, i.e., $0.4 \mathrm{~m} / \mathrm{s}, 0.6 \mathrm{~m} / \mathrm{s}$ with an acceleration of $6,8,10$, and $12 \mathrm{~m} / \mathrm{s}^{2}$. Excitation speed was low because, after the sudden stop of the actuator, the behavior of the hanging grape cluster was slightly damped. The value of the damping factor was observed low due to low energy loss from the cluster to the environment. The cycled damping model of Equation (3) was fitted with the experimental data of the damping stage for each speed and acceleration excitation. It was observed from theoretical analysis that experiment results agreed well with simulated results shown in Figure 12. It can be seen from Figure 12a-c that the amplitude of vibration in the damping zone increased when increasing the excitation speed of the actuator. But from 0.8 to $1.0 \mathrm{~m} / \mathrm{s}$, there is a small difference in amplitude due to twisting of the main rachis in other directions.

The energy in the damping phase was lost due to drag force, air resistance, and cluster weight. As we know damping force is directly proportional to velocity ${ }^{[59]}$.

$$
\begin{gathered}
F_{d} \infty v \\
F_{d}=-b \times v
\end{gathered}
$$

where, $F_{d}$ is damping force, $\mathrm{N} ; v$ is velocity excitation given by servo motor, $\mathrm{m} / \mathrm{s} ; b$ is damping constant of oscillation depending both on the shape of oscillator and medium through which oscillator is moving, $\mathrm{kg} / \mathrm{s}$.

If $t=0$, then Equation (3) becomes

$$
F(t)=a+c_{1}
$$

Consider the vibrations at some time $\tau$, for which the amplitude is reduced by factor $e$,

$$
\begin{gathered}
F\left(t_{1}\right)=a \times e^{-b t_{1}}+c_{1} \\
F\left(t_{1}\right)=a \times e^{-b\left(t_{1}+\tau\right)}+c_{1} \\
\frac{F\left(t_{1}\right)}{F\left(t_{1}+\tau\right)}=\frac{a \times e^{-b t_{1}}+c_{1}}{a \times e^{-b\left(t_{1}+\tau\right)}+c_{1}}
\end{gathered}
$$

where, $b=1 / \tau ; \tau$ is the relaxation time, $\mathrm{s}$.

The damping constant $b$ is inversely proportional to the time, during which the amplitude of the cluster's vibration is reduced by a factor $e$ as shown in Figure 11. However, the damping factor is not enough to describe the damping vibration of the hanging grape cluster. It is therefore necessary to introduce the time of one vibration cycle of the grape cluster. This characteristic is the decrement damping $D$ (decrease in damping), which is the ratio of the amplitudes of two successive peaks hanging force of grape cluster, which are separated in time by a period $T$. 


$$
\frac{F\left(t_{1}\right)}{F\left(t_{1}+T\right)}=\frac{a \times e^{-b t_{1}}}{a \times e^{-b\left(t_{1}+T\right)}}=e b T+c_{1}
$$

Logarithmic decrement is equal to the logarithm of $D$ :

$$
\begin{gathered}
\lambda=\ln D=b T+c_{1} \\
\lambda=b T=\frac{T}{\tau}+c_{1} \\
\lambda=\frac{1}{N e}
\end{gathered}
$$

Damping constant is inversely proportional to the number of cluster's vibrations that results in decreased amplitude of $e$. Here amplitude of the grape cluster's vibration is decaying with respect to time after the stop of the actuator, also, the total energy is not constant. The grape cluster lost its stored kinetic energy into environment due to friction and air resistance. Therefore, total energy was expressed as a function of time.

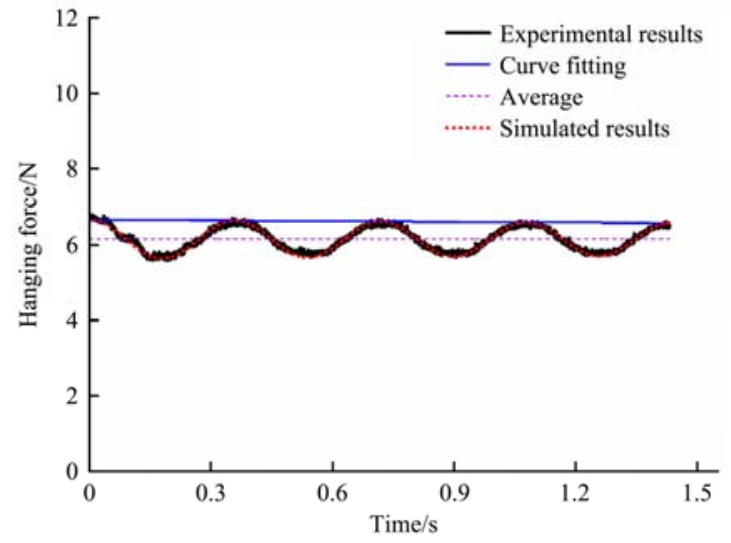

a. $v=0.4 \mathrm{~m} / \mathrm{s}$

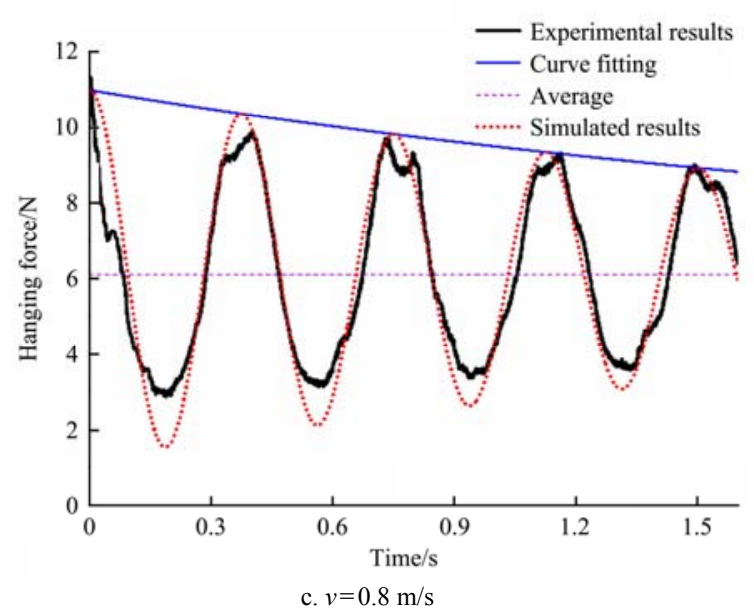

Figure 12 Vibration attenuation in damping phase at acceleration excitation of $12 \mathrm{~m} / \mathrm{s}^{2}$

\section{Conclusions}

In this study, the vibration mechanism of the hanging grape cluster in different phases of robotic transportation was observed from the experimental tests and theoretical analysis. The robotic linear transportation of the hanging grape cluster was recorded and analyzed by using a force sensor and digital camera images. The effect of different speed and acceleration excitations on the hanging force of the cluster was studied. The robotic post-harvest transportation process and berry drop damage caused by the vibration of the grape cluster were elucidated. Following conclusions are drawn from the proposed study:

1) It was concluded from the experiments that vibration of the hanging grape cluster was maximum at the deaccelerating phase of

$$
\begin{gathered}
E T_{(t)}=\frac{1}{2} m \times\left(a \times e^{-b t_{1}}\right)^{2} \\
E T_{(t)}=\frac{1}{2} m \times a^{2} \times e^{-2 b t_{1}} \\
E T_{(t)}=E_{0} \times e^{-2 b t_{1}}
\end{gathered}
$$

where, $E T_{(t)}$ is the total energy as a function of time; $E_{0}$ is the initial energy which is a function of mass and velocity.

If the velocity and mass of the grape cluster are high, then the initial energy stored in the cluster will be more, and it would cause the grape cluster to vibrate with high amplitude in the damping zone. Therefore, the chances of berry drop or shattering will be more in the damping phase of linear robotic transportation of the hanging grape cluster.

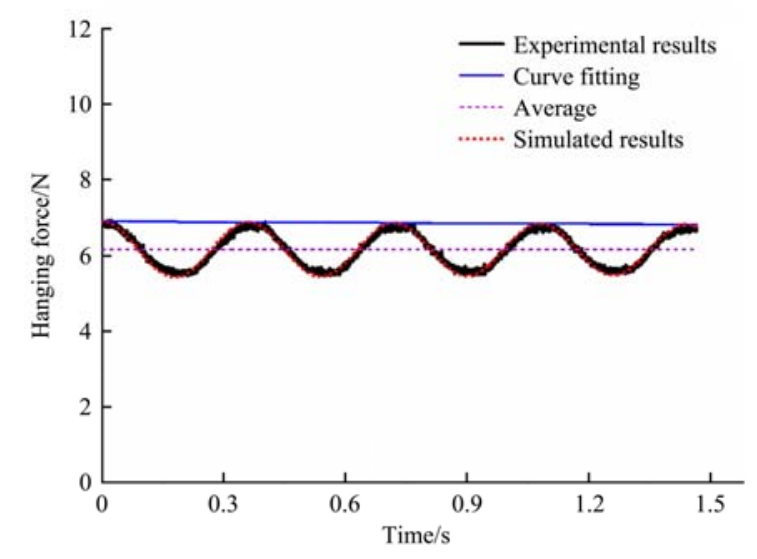

b. $v=0.6 \mathrm{~m} / \mathrm{s}$

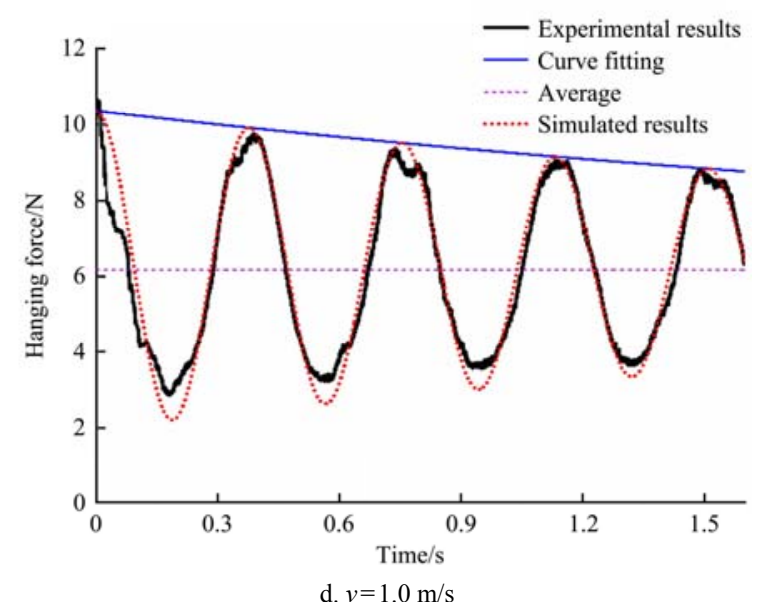

the actuator and more berry fall would happen in this phase of robotic transportation.

2) During the deaccelerating phase, it was observed from the camera images that maximum bending of the main rachis occurred at a swing angle of $59^{\circ}$.

3) It was concluded that by increasing the hanging force of the cluster, the swing angle of the cluster also increased linearly with $R^{2}=0.993$ and 0.964 for the accelerating and deaccelerating phases, respectively. The results of the swing angle and hanging force of the grape cluster suggested that the optimum acceleration excitation was $10 \mathrm{~m} / \mathrm{s}^{2}$ at each speed, at which damages would be minimum.

4) Based on the theoretical analysis of experimental results and simulated results, the behavior that grape cluster's vibration was damped after the sudden stop of the actuator verified berry falling 
damages would be more in damping zone.

Thus, current research can act as a guide for the robotic post-harvest handling of cluster fruits like fresh grapes, cherries, blueberries, and litchi. In the future, this research will help to reduce the damages on farm and food processing industry level. This study also provides the theoretical support for the industrial needs of the low-loss robotic handling of different fresh-eat cluster fruits that are consumed abundantly.

\section{Acknowledgements}

The research was supported by the National Science Foundation of China (Grant No. 31971795) and Priority Academic Program Development of Jiangsu Higher Education Institutions (Grant No. PAPD-2018-87). The authors are grateful to the National Science Foundation of China. The first author thanks the China Scholarship Council (2017GXZ026592) for providing 36 months scholarship for studying in China. The first author would like to thank his mother and wife Sidra for their moral support.

\section{[References]}

[1] Food and Agriculture Organization of the United Nations. FAOSTAT -(grapes, all countries, Prod Quant 2018). Available: http//www.fao.org/faostat/en/\#data/QC. Accessed on [2020-11-19].

[2] Jung H, Lee S, Lee W, Cho B. Effect of vibration stress on quality of packaged grapes during transportation. Eng Agric Environ Food, 2018; 11(2): 79-83.

[3] Deng Y, Wu Y, Li Y, Zhang P, Yang M, Shi C, et al. A mathematical model for predicting grape berry drop during storage. J Food Eng, 2007; 78(2): 500-511.

[4] Luo L, Tang Y, Zou X, Wang C, Zhang P, Feng W. Robust grape cluster detection in a vineyard by combining the AdaBoost framework and multiple color components. Sensors, 2016; 16(12): 2098. doi: 10.3390/s16122098

[5] Liu J, Peng Y, Faheem M. Experimental and theoretical analysis of fruit plucking patterns for robotic tomato harvesting. Computers and Electronics in Agriculture, 2020; 173: 105330. doi: 10.1016/ j.compag.2020.105330.

[6] Hussein Z, Fawole O. Harvest and postharvest factors affecting bruise damage of fresh fruits. Hortic Plant J, 2020; 6(1): 1-13.

[7] Liu J, Yuan Y, Yang G, Tang S, Li Z. Virtual model of grip-and-cut picking for simulation of vibration and falling of grape clusters. Trans of the ASABE, 2019; 62(3): 603-614.

[8] Lichter A, Gabler F M, Smilanick J L. Control of spoilage in table grapes. Stewart Postharvest Rev, 2006; 6(1): 1-10.

[9] Chen R, Wu P, Cao D, Tian H, Chen C, Zhu B. Edible coatings inhibit the postharvest berry abscission of table grapes caused by sulfur dioxide during storage. Postharvest Biol Technol, 2019; 152: 1-8.

[10] Hussein Z, Fawole O A, Opara U L. Preharvest factors influencing bruise damage of fresh fruits-a review. Sci Hortic, 2018; 229: 45-58.

[11] $\mathrm{Hu} \mathrm{X,} \mathrm{Xu} \mathrm{Y,} \mathrm{Liu} \mathrm{J.} \mathrm{Design} \mathrm{of} \mathrm{vibration} \mathrm{monitoring} \mathrm{system} \mathrm{and} \mathrm{its}$ application in grape fatigue damage research. In: Proceedings of the 2 nd International Conference on Control and Computer Vision. Jeju, Korea, 2019; pp.141-149.

[12] Jobbagy J, Kristof K, Schmidt A, Krizan M, Urbanovicova O. Evaluation of the mechanized harvest of grapes with regards to harvest losses and economical aspects. Agron Res, 2018; 16(2): 426-442.

[13] Neto W V D C, Elorza P B, Garrido-Izard M. Impact of local conditions and machine management on grape harvest quality. Sci Agric, 2019; 76(5): 353-361

[14] Fernando I, Fei J, Stanley R, Enshaei H. Measurement and evaluation of the effect of vibration on fruits in transit-Review. Packag. Technol. Sci., 2018; 31(11): 723-738.

[15] Gross K C, Wang C Y, Saltveit M E. The commercial storage of fruits, vegetables, and florist and nursery stocks. In: Agricultural Handbook 66. Washington DC: U. S. Department of Agriculture, Agricultural Research Service, 2016; 780p.

[16] Li M, You X, Wen R, Zhang Y, Sun J, Li Z, et al. Preservation quality and physiological biochemical characteristics of abscission fruit of grape during cold storage. South J Agric Sci, 2013; 44(11): 1883-1889. (in
Chinese)

[17] Nicolosi E, Ferlito F, Amenta M, Russo T, Rapisarda P. Changes in the quality and antioxidant components of minimally processed table grapes during storage. Sci Hortic (Amsterdam), 2018; 232: 175-183.

[18] Pezzi F, Caprara C, Bordini F. Transmission of impacts during mechanical grape harvesting and transportation. J Agric Eng, 2008; 39(3): 43-48.

[19] Caprara C, Pezzi F. Measuring the stresses transmitted during mechanical grape harvesting. Biosystems Engineering, 2011;110(2): 97-105.

[20] Yue X, Wu P, Wang S X, Liu Y Q, Su H. Experimental analysis of drop and vibration damage during grape storage and transportation. Packaging Engineering, 2019; 40(5): 9-18.

[21] Bian H X, Tu P. The influence of drop height on the dielectric properties of Red Globe grapes. Food Ferment Ind, 2013; 39(7): 154-157.

[22] Vinokur Y, Rodov V, Levi A, Kaplunov T, Zutahy Y, Lichter A. A method for evaluating fruit abscission potential of grapes and cherry tomato clusters. Postharvest Biol tech, 2013; 79: 20-23.

[23] Vallone M, Alleri M, Bono F, Catania P. Acceleration assessment during mechanical harvest of grapes using a non commercial instrumented sphere. Chem Eng Trans, 2017; 58: 277-282.

[24] Fischer D, Craig W L, Watada A E, Douglas W, Ashby B H. Simulated in-transit vibration damage to packaged fresh market grapes and strawberries. Appl Eng Agric, 1992; 8(3): 363-366.

[25] Fischer D, Craig W L, Ashby B H. Reducing transportation damage to grapes and strawberries. J Food Distrib Res, 1990; 21: 193-202.

[26] Ding H. Study on the effect of key factors on Kyoho grape quality during storage and transportation. Master dissertation. Tianjin: Tianjin University of Commerce, 2016; 64p. (in Chinese).

[27] Demir F, Kara Z, Carman K. Table grapes transport simulation study by Bardas (Vitis vinifera L.) cultivar grown in Karaman Turkey. In: 2nd International Symposium on Sustainable Development, 2010; pp.456-463.

[28] Xiong J, Zou X, Chen L, Cai W, Peng H. Visual position of picking manipulator for disturbed litchi. Transaction of the CSAE, 2012; 28(14): 36-41. (in Chinese)

[29] Tan J, Chen Y, Xiang H, Huang S, Zou X. Design and simulation of robot's end-effector for string-fruit picking. J Agric Mech Res, 2013; 39(7): 133-136.

[30] Yao T, Ding W. Test on vibration characteristics of cucumber picked by harvesting manipulator. Transactions of the CSAE, 2006; 22(9): 250-253. (in Chinese)

[31] Bulanon D M, Kataoka T. Fruit detection system and an end effector for robotic harvesting of Fuji apples. Agric Eng Int CIGR J, 2010;12(1): 203-210.

[32] Feng Q, Zheng W, Qiu Q, Jiang K, Guo R. Study on strawberry robotic harvesting system. In: 2012 IEEE International Conference on Computer Science and Automation Engineering (CSAE). Zhangjiajie, China, 2012; pp.320-324

[33] He L, Liu X, Du X, Wu C. In-situ identification of shaking frequency for adaptive vibratory fruit harvesting. Computers and Electronics in Agriculture, 2020; 170: 105245. doi: 10.1016/j.compag.2020.105245.

[34] Feng Q, Wang X, Zheng W, Qiu Q, Jiang K. New strawberry harvesting robot for elevated-trough culture. Int J Agric Biol Eng, 2012; 5(2): 1-8.

[35] Mu L, Cui G, Liu Y, Cui Y, Fu L, Gejima Y. Design and simulation of an integrated end-effector for picking kiwifruit by robot. Inf Process Agric, 2020; 7(1): 58-71

[36] Li J, Tang Y, Zou X, Lin G, Wang H. Detection of fruit-bearing branches and localization of Litchi clusters for vision-based harvesting robots. IEEE Access, 2020; 8: 117746-117758.

[37] Luo L, Tang Y, Zou X, Ye M, Feng W, Li G. Vision-based extraction of spatial information in grape clusters for harvesting robots. Biosystems Engineering, 2016; 151: 90-104.

[38] Peng J, Sun S, Feng Y, Yang Y, Fu L. Analysis and simulation of vibration harvesting mechanism of seabuckthorn fruit-stalk system. Journal of Agricultural Mechanization Research, 2017; 39(7): 28-33.

[39] Monta M, Kondo N, Shibano Y. Agricultural robot in grape production system. In: Proceedings of the 1995 IEEE International Conference on Robotics and Automation. Nagoya-Japan, 2002; pp.2504-2509.

[40] Kondo N, Tanihara K, Shiigi T, Shimizu H, Kurita M, Tsutsumi M, et al. Path planning of tomato cluster harvesting robot for realizing low vibration and speedy transportation. Eng Agric Environ Food, 2009; 2(3): $108-115$.

[41] Xiong J, He Z, Lin R, Liu Z, Bu R, Yang Z, et al. Visual positioning technology of picking robots for dynamic litchi clusters with disturbance. 
Computers and Electronics in Agriculture, 2018; 151: 226-37.

[42] Yin J J, Chen Y H, He K, Liu J Z. Design and experiment of grape-picking device with a grasping and rotary-cut type of underactuated double fingered hand. Transactions of the CSAE, 2017; 48(11): 11-20. (in Chinese)

[43] Liu J, Tang S, Shan S, Ju J. Simulation and test of grape fruit cluster vibration for robotic harvesting. Transactions of the CSAM, 2016; 47(5): 1-8. (in Chinese)

[44] Hoshyarmanesh H, Dastgerdi H R, Ghodsi M, Khandan R, Zareinia K. Numerical and experimental vibration analysis of olive tree for optimal mechanized harvesting efficiency and productivity. Computers and Electronics in Agriculture, 2017; 132: 34-48.

[45] Upadhyaya S K, Rand R H, Cooke J R. Dynamics of fruit tree trunk impact. Transactions of the ASAE, 1981; 24(4): 846-855

[46] Rand R H, Cooke J R. Vibratory fruit harvesting: a non-linear theory of fruit-stem dynamics. J Agric Eng Res, 1970; 15(4): 347-363.

[47] Crooke J R, Rand R H. Vibratory fruit harvesting: a linear theory of fruit-stem dynamics. J Agric Eng Res, 1969; 14(3): 195-209.

[48] Bentaher H, Haddar M, Fakhfakh T, Mâalej A. Finite elements modeling of olive tree mechanical harvesting using different shakers. Trees, 2013; 27(6): 1537-1545.

[49] Xuan Y, Xu L, Liu G, Zhou J. The vibrational response of simulated Ginkgo biloba fruit based on their frequency spectrum characteristics. PLoS One, 2020; 15(7): e235494. doi: 10.1371/journal.pone.0235494.

[50] Coelho A L D F, Santos F L, Queiroz D M D, Pinto F D A D C. Dynamic behavior of the coffee fruit-stem-branch system using stochastic finite element method. Coffee Sci Lavras, 2016; 11(1): 1-10.

[51] Ramli M R H, Hudzari R M, Wahab F I A, Ghani M N A. Determination of frequency properties of Jatropha curcas fruits stalk for mechanical harvesting operations. Int J Agric Sci, 2011; 3(2): 103-109.

[52] Zhou J, He L, Karkee M, Zhang Q. The effect of shaking frequency on fruit motion patterns and damage rate during cherry detaching process. In Proceedings of 2013 ASABE Annual International Meeting. Kansas, USA, 2013; Paper number: 131591861. doi: 10.13031/aim.20131591861.

[53] Huang C Y, Jheng W T, Tai W K, Chang C C, Way D L. Procedural grape bunch modeling. Comput Graph, 2013; 37(4): 225-237.

[54] Schöler F, Steinhage V. Automated 3D reconstruction of grape cluster architecture from sensor data for efficient phenotyping. Computers and Electronics in Agriculture, 2015; 114: 163-177.

[55] Mack J, Rist F, Herzog K, Töpfer R, Steinhage V. Constraint-based automated reconstruction of grape bunches from $3 \mathrm{D}$ range data for high-throughput phenotyping. Biosystems Engineering, 2020; 197: 285-305.

[56] Arikapudi R, Petiteville A D, Vougioukas S G. Model-based assessment of robotic fruit harvesting cycle times. In: Proceedings of 2014 ASABE Annual International Meeting. Montreal, Canada, 2014; Paper number: 141913999. doi: 10.13031/aim.2014913999.

[57] Rekhviashvili S, Pskhu A, Agarwal P, Jain S. Application of the fractional oscillator model to describe damped vibrations. Turkish $\mathrm{J}$ Physics, 2019; 43(3): 236-242.

[58] Digitize graphs and plots - GetData Graph Digitizer - graph digitizing. Available: http://getdata-graph-digitizer.com/index.php. Accessed on [2020-11-19].

[59] Li J, Yang X, Hou A, Chen Y, Li M. Aerodynamic damping prediction for turbomachinery based on fluid-structure interaction with modal excitation. Applied Science, 2019; 9(20): 4411. doi: 10.3390/app9204411. 